\title{
The effect of glutathione and mannitol on androgenesis in anther and isolated microspore cultures of rye (Secale cereale $L$.
}

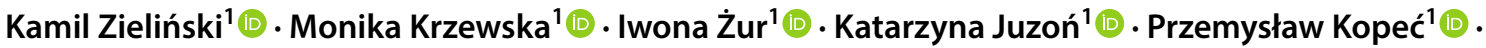

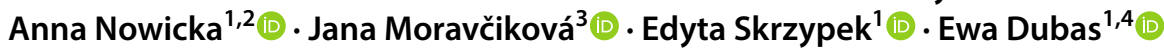

Received: 25 June 2019 / Accepted: 25 December 2019 / Published online: 7 January 2020

(c) The Author(s) 2020

\begin{abstract}
Androgenic responsiveness in anther (AC) and isolated microspore cultures (MC) was analysed using 15 lines of Polish winter rye (Secale cereale L.). The effect of low temperature (LT) alone or in combination with osmotic stress induced by mannitol treatment (MAN) and/or with reduced glutathione (GSH) on the effectiveness of the process was studied. Interestingly, each treatment had a different effect on microspore (mcs) vitality and capability to divide symmetrically. The first criterion for successful embryogenesis was to exceed the threshold number of at least $25 \%$ dividing microspores, which determined 'embryogenic suspension culture'. In some configurations a spectacular effect was achieved, especially in lines highly recalcitrant to androgenesis induction. Relatively high effectiveness of androgenesis induction (up to 4.58 AS per $10^{5} \mathrm{mcs}$ per spike in MC and 21.29 AS per spike in AC) showed that the developed protocol with GSH and/or MAN tiller pre-treatments overcomes the genotypic barrier for androgenesis initiation in rye. Moreover, relatively high, spontaneous genome diploidization (55\%) of regenerated plants demonstrated that the described protocols could be effectively integrated into conventional rye breeding programmes.
\end{abstract}

\section{Key message}

Glutathione and mannitol break the barrier of androgenesis initiation by increasing the dividing and vital microspores ratio. This marker is useful for screening material in breeding programs utilizing DH technology.

Communicated by Alison M.R. Ferrie.

Electronic supplementary material The online version of this article (https://doi.org/10.1007/s11240-019-01754-9) contains supplementary material, which is available to authorized users.

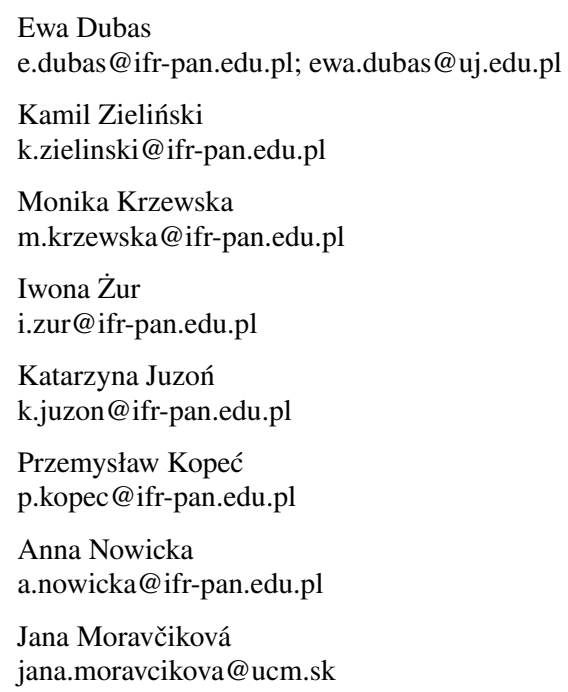

Edyta Skrzypek

e.skrzypek@ifr-pan.edu.pl

1 The F. Górski Institute of Plant Physiology, Polish Academy of Sciences, Niezapominajek 21, 30-239 Kraków, Poland

2 Institute of Experimental Botany of the Czech Academy of Sciences V. V. I. (IEB), Centre of the Region Haná for Biotechnological and Agricultural Research (CRH), Šlechtitelů 31, 78371 Olomouc, Czech Republic

3 Department of Biotechnology, Faculty of Natural Sciences, University of SS. Cyril and Methodius in Trnava, Nám. J. Herdu 2, 91701 Trnava, Slovak Republic

4 Department of Plant Cytology and Embryology, Institute of Botany, Jagiellonian University, Gronostajowa 3, 30-387 Kraków, Poland 
Keywords Androgenesis responsiveness · Glutathione $\cdot$ Mannitol $\cdot$ Microspore embryogenesis $\cdot$ Rye

\begin{tabular}{|c|c|}
\hline \multicolumn{2}{|c|}{ Abbreviations } \\
\hline 2N SYM & $\begin{array}{l}\text { Microspores with nuclei after symmetric } \\
\text { division }\end{array}$ \\
\hline $\mathrm{AC}$ & Anther cultures \\
\hline AS & Androgenic structures \\
\hline DAPI & 4',6-Diamidino-2-phenylindole \\
\hline $\mathrm{DH}$ & Doubled haploids \\
\hline DIC & Differential interference contrast system \\
\hline FDA & Fluorescein diacetate \\
\hline GSH & Glutathione \\
\hline $\mathrm{H}$ & Haploid plants (1n) \\
\hline HS & Hoagland solution \\
\hline LMW & Low molecular weight antioxidants \\
\hline LT & Low temperature treatment \\
\hline MAN & Mannitol \\
\hline $\mathrm{MC}$ & Microspore cultures \\
\hline mes & Microspores \\
\hline $\mathrm{ME}$ & Microspore embryogenesis \\
\hline PCD & Programmed cell death \\
\hline $\mathrm{R}$ & Regenerants \\
\hline $\mathrm{R}_{\text {Albino }}$ & Albino plant regeneration \\
\hline $\mathrm{R}_{\text {Green }}$ & Green plant regeneration \\
\hline ROS & Reactive oxygen species \\
\hline $\mathrm{R}_{\text {Total }}$ & Total plant regeneration \\
\hline $\mathrm{TH}$ & Tetraploid (4n) \\
\hline UN & Microspores at uninucleate stage \\
\hline
\end{tabular}

\section{Introduction}

Due to low soil and climate requirements as well as low sensitivity to unfavourable environmental conditions (e.g. low temperatures, salinity, water deficit), rye (Secale cereale L.) currently belongs to the most important crops in the EU cereals market. Recently (2018/2019; 22 June 2019), the marketing area and usable production of rye in the EU has increased by $13.1 \%$ and $29.5 \%$, respectively (https:// ec.europa.eu/agriculture/market-observatory/crops). The HealthyMinorCereals project, funded by EU FP7, indicated that farmers have an interest in growing traditional cereal species such as rye because they are well-suited to less intensive cultivation, including organic and conservation farming. Moreover, rye is the best crop for healthy human nutrition because of much higher levels of total antioxidants, carbohydrates, proteins, vitamins, and especially dietary fibers (https://www.openaccessgovernment.org/healthyminorcer eals-project/43195/; Tenhola-Roininen 2009). Because of the growing interest in rye cultivation, its production and demand in the grain-milling and fuel industries have been changing dynamically.
Rye breeding goals are focused on the production of improved high-yielding, short-strawed varieties with reduced tendency for pre-harvest sprouting. However, gametophytic self-incompatibility and cross pollination significantly slow down rye breeding progress (Lundqvist 1956). Improvement of this crop is possible by conventional population breeding or hybrid breeding. In both breeding systems the implementation of totally homozygous doubled haploids (DHs) can shorten the time needed for the production of a new variety and increase the efficiency of desired trait selection. Among various methods of $\mathrm{DH}$ production, induction of androgenesis-microspore reprogramming towards sporophytic development in in vitro cultured anthers or isolated microspores-is potentially the most effective. However, as the process is controlled by a complex network of internal and environmental factors, the realisation of this theoretically huge embryogenic potential is quite unique in laboratory practise (Ferrie and Caswell 2011; Żur et al. 2013).

Research on DH production in rye began in the mid1970s without spectacular success. Most of the work focused primarily on the efficiency of androgenesis induction in anther cultures (AC) on solid media, testing many modifications of the procedure (Wenzel and Thomas 1974; Thomas et al. 1975; Wenzel et al. 1977; Chu 1978; Chuang et al. 1978; Wang and $\mathrm{Hu}$ 1984; Ouyang et al. 1989; Flehinghaus et al. 1991; Daniel 1993; Flehinghaus-Roux et al. 1995). The turning point came with improved media-containing e.g. L-glutamine (500 $\left.\mathrm{mg} \mathrm{L}^{-1}\right), 2.3 \mu \mathrm{M}$ kinetin $\left(0.5 \mathrm{mg} \mathrm{L}^{-1}\right)$ with $9 \mu \mathrm{M}$ auxin $\left(2 \mathrm{mg} \mathrm{L}^{-1}\right), 6 \%$ maltose (w/v) and $0.3 \%$ (w/v) Phytagel $\left(3 \mathrm{~g} \mathrm{~L}^{-1}\right)$ — which increased both the induction effectiveness and plant regeneration ability in spring ryes (Immonen and Tenhola-Roininen 2003). According to these authors, two solid induction media-90-2 (Zhuang and Xu 1983) and W-14 (Ouyang et al. 1989)_-were found to be the best for androgenesis induction in AC of rye. However, high genotype dependency still limits the possibility for wider commercial application of the method in rye breeding programmes. A similar problem was observed in isolated microspore cultures (MC) and despite extensive investigations (Wenzel et al. 1976; Deimling et al. 1994; Immonen and Anttila 1996a; Rakoczy-Trojanowska et al. 1997; Immonen 1999; Guo and Pulli 2000; Ma et al. 2004; Tenhola-Roininen et al. 2005), the resistance of some genotypes to androgenesis induction was not overcome. Due to low microspore survival and decreased fertility of regenerated plants, a limited number of green regenerants (10-40\%) with spontaneous genome duplication (90\%) was obtained, which did not meet the requirements of breeding programs. Because high microspore viability and their ability to divide are the first determinants of ME induction, various physical and/or chemical inducers are usually applied to increase the 
resistance of microspores to stress associated with the isolation and transfer to in vitro conditions. For rye, low temperature (LT) tillers pre-treatment $\left(4{ }^{\circ} \mathrm{C}\right)$ and isolated anthers incubation in $0.3 \mathrm{M}$ mannitol were found to have a positive effect on ME effectiveness (Tenhola-Roininen et al. 2005). Furthermore, the use of enhanced stress combination of cold pre-treatment of spikes $\left(4^{\circ} \mathrm{C}\right)$ and heat treatment of anthers $\left(32^{\circ} \mathrm{C}\right)$ with in vitro culture on 190-2 medium (Zhuang and $\mathrm{Xu}$ 1983) had beneficial impact on green plant regeneration in AC (Tenhola-Roininen et al. 2005). From studies on triticale (genetically related to rye; Żur et al. 2014, 2019), it is known that genetically controlled but environmentally modified microspore tolerance to oxidative stress determines androgenesis effectiveness (Żur et al. 2014). Imbalance between the production of reactive oxygen species (ROS) and the efficiency of the antioxidative system leads to oxidative stress causing disturbances in many important cellular processes. The transduction of ROS-induced signal initiates microspore reprogramming and simultaneously protects the cells from the toxic effects of ROS production. Although the protective role of antioxidative enzymes cannot be replaced even by high activity of non-enzymatic antioxidants, the use of substances which reduce oxidative stress (e.g. low molecular weight (LMW) antioxidants) could stimulate androgenesis induction and improve regeneration of green plants (Stasolla et al. 2008; Cistué et al. 2009; Asif et al. 2013; Zeng et al. 2017; Żur et al. 2019). Among LMW antioxidants, the reduced form of glutathione (GSH) is one of the most important ROS scavengers and plays a significant role in maintaining the cellular redox potential, which determines proper cell growth and differentiation, and in the control over programmed cell death (PCD) initiation. It has been recently shown that exogenous GSH applied during low temperature tiller pre-treatment (short and long-lasting) stimulated ME in triticale (Żur et al. 2019).

Taking all this information into account, in the present work, tillers of rye were exposed to stress of different, chemically-modulated intensities. The effect of LT alone or in combination with MAN and/or GSH on the effectiveness of androgenesis was studied in $\mathrm{AC}$ and MC of several Polish breeding lines of winter rye (S. cereale L.). For the first time, prolonged low temperature pre-treatment of tillers (LT; Control) was paired with various combinations of GSH and MAN applications and examined in the context of cytological characteristics of microspores and androgenesis induction effectiveness on different media and under different temperature regimes.

\section{Material and methods}

\section{Plant material and growth conditions}

Polish winter rye (S. cereale L.) lines (no. 1-15) of various origin and pollination system were used in this study (details in Table 1).

Germinating kernels were placed in perlite pre-soaked with Hoagland solution (HS) and vernalized for 9 weeks at $2{ }^{\circ} \mathrm{C}$ with light intensity $100 \mu \mathrm{mol} \mathrm{m} \mathrm{s}^{-2} \mathrm{~s}^{-1}$ (PAR) and shortday induction $(8 \mathrm{~h} / 16 \mathrm{~h}$; light/dark). Vernalized seedlings, twenty per line, were planted individually into $3 \mathrm{dm}^{3}$ pots containing a mixture of soil and sand $(3 / 1 ; \mathrm{v} / \mathrm{v})$. Rye plants (a total of 4500 plants) were grown in a greenhouse (April/ May), under controlled conditions, at $25 / 17^{\circ} \mathrm{C}$ (day/night), $800 \mu \mathrm{mol} \mathrm{m}{ }^{-2} \mathrm{~s}^{-1}$ PAR and long day $(16 \mathrm{~h} / 8 \mathrm{~h}$ light/dark). Photoperiod and light intensity were maintained using high pressure sodium lamps (400 W; Philips SON-T AGRO, Belgium) between 6-8 a.m., 6-10 p.m. and on cloudy days. Plants were watered twice a week with $\mathrm{N}: \mathrm{P}: \mathrm{K}=15: 15: 18$ soluble fertilizer.

\section{Tiller pre-treatment protocol for anther (AC) and microspore cultures (MC)}

Tillers were ready to harvest in 6-10 weeks after planting into the pot. Tillers were harvested when the distance between the flag leaf and the leaves below it was $10-14 \mathrm{~cm}$,

Table 1 Origin and type of pollination for winter rye (Secale cereale L.) line

\begin{tabular}{llll}
\hline Line label & Hybrid line & Origin & Pollination type \\
\hline 1 & SOA 2550/2014 & DANKO & Self-pollinating \\
2 & $94($ PHR 2/15) & PHR & Cross-pollinating \\
3 & $41($ PHR 4/15) & PHR & \\
4 & $31($ PHR 5/15) & PHR & \\
5 & 61 (PHR 3/15) & PHR & \\
6 & F1S 1123/14 & DANKO & Self-pollinating \\
7 & F1S 1138/14 & DANKO & \\
8 & HRSM 127-2R & IHAR & Cross-pollinating with \\
9 & HRSM 186-R & IHAR & self-compatibility \\
10 & HRSM 131-R & IHAR & gene \\
11 & HRSM 135-2R & IHAR & \\
12 & HRSM 143-3R & IHAR & \\
13 & F1S 1131/14 & DANKO & Self-pollinating \\
14 & SOA 2545/2014 & DANKO & \\
15 & 36 (PHR 1/15) & PHR & Cross-pollinating \\
\hline
\end{tabular}

Origin: DANKO_DANKO Plant Breeding Ltd, Choryń, Poland; PHR_Poznań Plant Breeding Sp. z o. o.; IHAR_Plant Breeding and Acclimatization Institute, National Research Institute, Radzików, Poland 


\section{A}

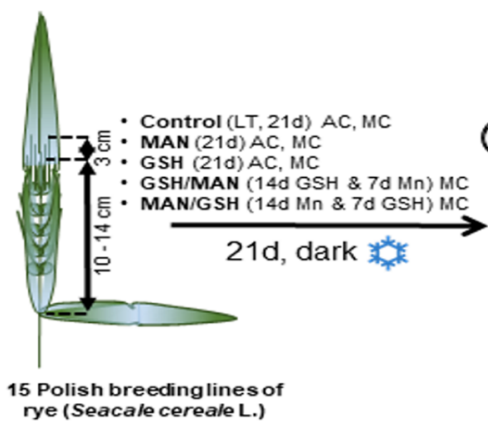

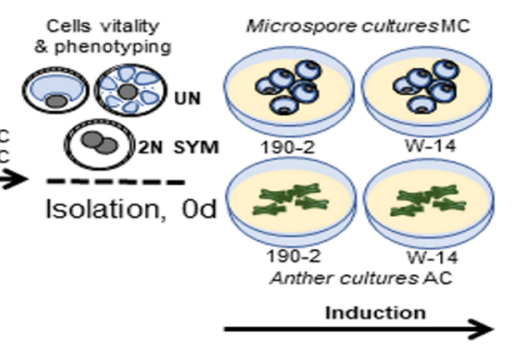

6 weeks, dark: $4^{\circ} \mathrm{C} 7 \mathrm{~d} / 26^{\circ} 35 \mathrm{~d} ; \mathrm{MC}$

$26^{\circ} 42 \mathrm{~d}$ AC; $M C$

$32^{\circ} \mathrm{C} 2 \mathrm{~d} / 26^{\circ} 40 \mathrm{~d} ; \mathrm{MC}$

Androgenesis efficiency parameters:

AS per spike; AC

政 1 per spike; $M C$

- Ros per spike

- Ravon per spike

- R Roco per spike

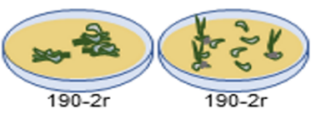

$\underset{6 \text { weeks, light, } 26^{\circ} \mathrm{C}}{\stackrel{\text { Regeneration }}{\longrightarrow}}$

\section{B}
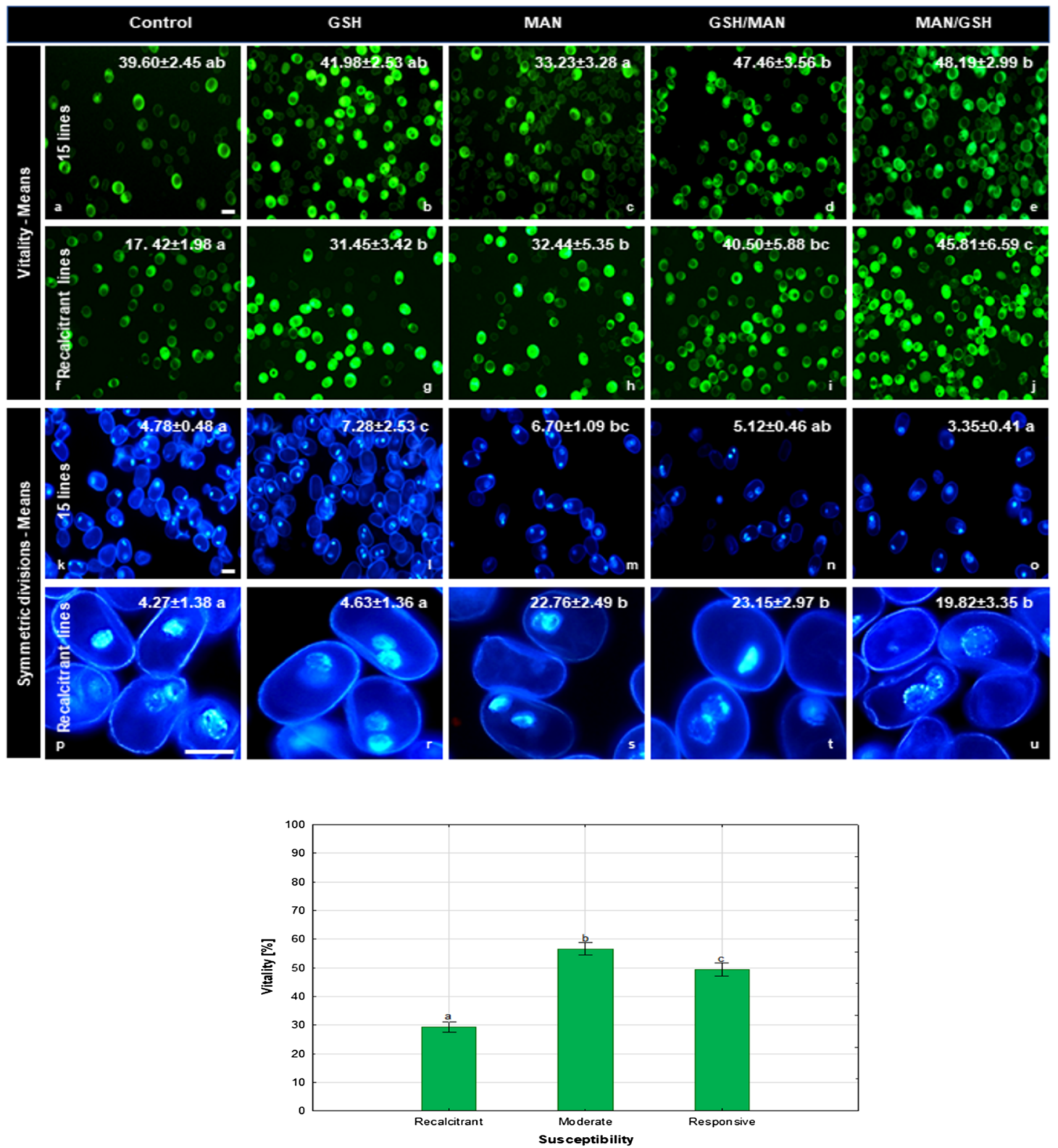
4Fig. 1 The effect of glutathione and mannitol tiller pre-treatments on androgenesis efficiency in anther and isolated microspore cultures of rye (Secale cereale L.). a The scheme of the experiment. Representations of tiller pre-treatments (low temperature $\left(4{ }^{\circ} \mathrm{C}\right.$ ) Control, glutathione GSH, mannitol MAN and combined treatments with LT, reduced glutathione and mannitol GSH/MAN and MAN/GSH) at $4{ }^{\circ} \mathrm{C}$ for 21 days and in vitro culture conditions on 190-2 and W-14 media. This description also applies in further Figures of this paper. Left: the phenotype of tillers/microspores when collected. UN-uninucleate microspore, 2N SYM-microspores with nuclei after symmetric division. Right: Parameters of the efficiency of androgenesis process (induction expressed as AS per spike and regeneration expressed as $\mathrm{R}_{\text {Total }}$ per spike) in anther (AC) and microspore (MC) cultures. The mean total numbers $\pm \mathrm{SE}$. $b$ The effect of rye tiller pre-treatments (Control, GSH, MAN, GSH/MAN or MAN/GSH) on microspore vitality $(\mathbf{a}-\mathbf{j})$ and microspore competence to enter symmetric divisions (k-u). Means for all 15 lines (a-e and $\mathbf{k}-\mathbf{o}$ ). Means for lines characterised as recalcitrant to androgenesis induction $(\mathbf{f}-\mathbf{j}$ and $\mathbf{p}-\mathbf{u})$. Microspores stained with FDA (fluorescence of vital cells intensely green) $(\mathbf{a}-\mathbf{j})$. Nuclei counterstained with DAPI (intensely blue) $(\mathbf{k}-\mathbf{u})$. Bar $=20 \mu \mathrm{m}$. $\mathbf{c}$ The influence of the genotype of donor plants on the frequency of viable microspores. The 15 tested lines of rye are grouped into three categories: recalcitrant, moderate and responsive to androgenesis induction. Error bars denote standard deviation of the mean (SD) between three biological replicates. Experimental points marked with the same letter do not differ according to Duncan's multiple range test $(\mathrm{P} \leq 0.05)$

between the flag leaf and ears $-3 \mathrm{~cm}$ and the majority of microspores were at the late uni-nucleate stage. Tillers collected daily were randomly selected for proposed pretreatments, wrapped in plastic bags and stored for 3 weeks at $4{ }^{\circ} \mathrm{C}$ in the dark in jars containing (i) Hoagland solution (HS) (Control; LT 21d), (ii) HS with $0.3 \mathrm{mmol} \mathrm{1}^{-1}$ reduced glutathione (GSH; 21d) or (iii) HS with $0.7 \mathrm{~mol}^{-1}$ mannitol (MAN; 21d) for AC and MC.

Additionally, only for MC, two other pre-treatments were applied: (iv) GSH/MAN and (v) MAN/GSH. In both procedures, tillers were treated with $0.3 \mathrm{mmol}^{-1}$ reduced glutathione and $0.7 \mathrm{~mol} 1^{-1}$ mannitol but in a different sequence. In GSH/MAN, tillers were treated with $0.3 \mathrm{mmol} \mathrm{l}^{-1}$ reduced glutathione for the first 14 days, then transferred to 0.7 mol $1^{-1}$ mannitol for the last 7 days of LT treatment; whereas in MAN/GSH tillers were treated with $0.7 \mathrm{~mol}^{-1}$ mannitol for the first 14 days and then transferred to $0.3 \mathrm{mmol}^{-1}$ reduced glutathione (Fig. 1a). The experiment was carried out in three independent replications. For one replicate 12 spikes per one line were used.

\section{Cell viability and phenotyping}

For microscopic analyses, the collected microspores were sampled on the isolation day. For microspore culture, each sample was taken from a pellet of isolated microspores (from 42 spikes) resuspended in $1 \mathrm{ml}$ medium, before it was divided between the in vitro treatments. At least three samples per each line and tiller pre-treatment were processed.
Microspore viability was determined on the isolation day through fluorochromatic reaction to fluorescein diacetate (FDA; $0.01 \% ; \lambda_{\mathrm{Ex}}=465 \mathrm{~nm}, \lambda_{\mathrm{Em}}=515 \mathrm{~nm}$, green fluorescence; Heslop-Harrison and Heslop-Harrison 1970).

For cell phenotyping (assessment of cell divisions), chromatin was stained with 4'0.6-diamidino-2-phenylindole $* 2 \mathrm{HCl}$ (DAPI; $0.0001 \% ; \lambda_{\mathrm{Ex}}=365 \mathrm{~nm}, \lambda_{\mathrm{Em}}=420 \mathrm{~nm}$, blue fluorescence; Custers et al. 1994).

Samples of suspension $(100 \mu \mathrm{l})$ containing microspores at uninucleate stage (UN) or after symmetric division $(2 \mathrm{~N}$ SYM) were collected in Eppendorf tubes and incubated in FDA or DAPI. Then, a drop of suspension was placed on a slide and analyzed.

The samples were examined under Nikon Eclipse-E600 equipped with a differential interference contrast (DIC) system. Fluorescence was examined under filters EX 365/DM 400/BA 420 EF (DAPI); EX 470-490/DM 510 BA/515 EF (FDA). Images were collected with Zyla 4.2 (Andor) digital camera and processed with NIS-Elements AR 4.00 Imaging Analysis, Microsoft PowerPoint and Corel PhotoPaint X5 programs.

The final frequency of AS (AS per $10^{5} \mathrm{mcs}$ ) in MC was assessed after 6 weeks of in vitro culture with an inverted light microscope (NIKON TS-100/100F). Additional microscopic observations of microspore suspensions were performed at certain points of in vitro culture: on the isolation day (0d), after 7 days ( $7 \mathrm{~d})$, after 14 days (14d), after 28 days (28d) and after 42 days (42d).

\section{Microspore isolation and culture}

Microspore culture response of the 15 lines was evaluated using five pre-treatments, two induction media and three temperature regimes. At least 630 tillers were harvested from each line (20 plants per line) over a four-week period. In total, 210 tillers were divided between tillers pre-treatment procedures (Control, GSH, MAN, GSH/MAN, MAN/ GSH) described above. One batch (42 spikes) was used for one treatment.

Following pre-treatment, spikes were sprayed with $96 \%$ (v/v) ethanol, surface-sterilised in $20 \%$ (v/v) commercial bleach ('Domestos') for $15 \mathrm{~min}$ and rinsed 4-5 times with sterile deionised water. Then, the spikes were cut into ca. $2 \mathrm{~cm}$ long segments and blended in $0.3 \mathrm{~mol}^{-1}$ mannitol with the use of Waring blender (Fisher Scientific Inc.). The resulting slurry was filtrated through a $74 \mu \mathrm{m}$ metal sieve (200 mesh; CD-1, Sigma-Aldrich) and pelleted (100×g, $5 \mathrm{~min}$ ). After removing the supernatant, the microspores were resuspended in $0.3 \mathrm{~mol}^{-1}$ mannitol and gently layered onto $21 \%$ (w/v) maltose solution for density gradient centrifugation $(80 \times g, 5 \mathrm{~min})$. Viable microspores settled at the interface between mannitol and maltose were collected, washed in $0.3 \mathrm{~mol} \mathrm{l}^{-1}$ mannitol and pelleted $(100 \times g, 5 \mathrm{~min})$. 
Then, the pelleted microspores were divided between the two media and three incubation temperature treatments. Microspores were resuspended in $1 \mathrm{ml}$ modified induction medium 190-2 (Zhuang and Xu 1983) or W-14 (Ouyang et al. 1989). The modifications were similar to those for $\mathrm{AC}$, with the exception for maltose being in concentration of $63 \mathrm{~g} \mathrm{l}^{-1}$. Microspore suspensions with the final density of approximately $70 \times 10^{3}$ microspores per $\mathrm{ml}(\mathrm{mcs} / \mathrm{ml})$ were transferred to $15 \times 60 \mathrm{~mm}$ Petri dishes and co-cultured with immature ovaries (10 per $1 \mathrm{ml}$ of suspension) which had been dissected simultaneously with microspore isolation. The cultures were kept under different temperature conditions: (1) at $4{ }^{\circ} \mathrm{C}$ for $7 \mathrm{~d}$, then transferred to $26{ }^{\circ} \mathrm{C}$ for the next $35 \mathrm{~d}$ or (2) at $26{ }^{\circ} \mathrm{C}$ for $42 \mathrm{~d}$ or (3) at $32{ }^{\circ} \mathrm{C}$ for $2 \mathrm{~d}$, then transferred to $26{ }^{\circ} \mathrm{C}$ for the next $40 \mathrm{~d}$ in the dark (Fig. 1a). Microspore suspension obtained from 42 spikes was considered a replicate and 126 spikes were processed for each line/ pre-treatment/medium/incubation temperature combination.

The number of AS was determined microscopically (see "Cell viability and phenotyping" section) prior to transfer to regeneration medium. The subsequent transfer of AS to regeneration medium ( 6 weeks), green plants rooting ( 2 weeks) and vernalization (9 weeks) were the same as in the anther culture protocol.

\section{Anther culture protocol}

Anther culture response of the 15 lines was evaluated using three pre-treatments and two induction media. At least 36 tillers were harvested from each line (20 plants per line) over a four-week period. 12 tillers were allocated to each of the three low temperature pre-treatments (Control, GSH, MAN) lasting 21 days, which were described earlier. Following pretreatment, spikes were surface-sterilised and 100 anthers were aseptically excised from each spike and transferred to either 190-2 (Zhuang and Xu 1983) or W-14 (Ouyang et al. 1989) induction medium in $55 \mathrm{~mm}$ Petri dishes. Each spike was considered a replicate and six spikes were processed for each line/pre-treatment/medium combination. To evaluate the effect of various pre-treatments, anthers excised from low temperature pre-treated (Control) tillers were used as the control.

The protocol was as described by Immonen and TenholaRoininen (2003) with minor modifications. For surface sterilisation, 96\% ethanol and comercial bleach (1:5 'Domestos' dilluted in water) were used instead of sodium hypochlorite solution with Tween 80. Other modifications included changes to both media with additional $238 \mathrm{mg} \mathrm{dm}^{-3} \mathrm{~L}$-glutamine, and growth regulators supplemented with $1.0 \mathrm{mg} \mathrm{l}^{-1}$ Dicamba, $1.0 \mathrm{mg} \mathrm{l}^{-1}$ Picloram, $0.5 \mathrm{mg} \mathrm{l}^{-1} \mathrm{NAA}$ and $90 \mathrm{~g} \mathrm{l}^{-1}$ maltose, $\mathrm{pH}$ 5.8.

Some supplements or their concentration in the tested media differed from the protocol by Immonen and
Tenhola-Roininen (2003) - e.g. L-glutamine was decreased from $500 \mathrm{mg} \mathrm{l}^{-1}$ to $438 \mathrm{mg} \mathrm{l}^{-1}, 2,4-\mathrm{D}$ was replaced by $1.0 \mathrm{mg} \mathrm{l}^{-1}$ Dicamba, $1.0 \mathrm{mg} \mathrm{l}^{-1}$ Picloram, $0.5 \mathrm{mg} \mathrm{l}^{-1} \mathrm{NAA}$, Kinetin was omitted and maltose was increased from 60 to $90 \mathrm{~g} \mathrm{l}^{-1}$.

The cultures were stored in the dark at $26 \pm 1{ }^{\circ} \mathrm{C}$. Androgenic structures (AS $\geq 5 \mathrm{~mm}$ ) were transferred successively starting from the sixth week of culture, in three-week intervals. The structures (30 AS per a $90 \mathrm{~mm}$ Petri dish) were transferred onto the regeneration medium 190-2r (Zhuang and $\mathrm{Xu} 1983$ ) containing $30 \mathrm{mg} \cdot \mathrm{l}^{-1}$ sucrose, $0.5 \mathrm{mg} \mathrm{l^{-1 }}$ Kinetin, $0.5 \mathrm{mg} \cdot \mathrm{l}^{-1} \mathrm{NAA}$ and $0.6 \%(\mathrm{w} / \mathrm{v})$ agar, $\mathrm{pH}$ 6.0. The regeneration phase took place at $26^{\circ} \mathrm{C}$, in the light-at about $30 \mu \mathrm{mol}(\mathrm{h} \nu) \mathrm{m}^{-2} \mathrm{~s}^{-1}$ for the first week, then increased to 80-100 $\mu \mathrm{mol}(\mathrm{h} \nu) \mathrm{m}^{-2} \mathrm{~s}^{-1}$ (PAR) — with a photoperiod of $16 \mathrm{~h} / 8 \mathrm{~h}$ (day/night) (Fig. 1a).

After 6 weeks of regeneration, green plants were transferred to Magenta boxes with perlite soaked with halfstrength Hoagland's nutrient solution for better rooting. Later, plants were potted into containers filled with a soilpeat mixture and grown in a greenhouse until the 4th leaf was fully formed. Next, seedlings were vernalized at $2{ }^{\circ} \mathrm{C}$ for 9 weeks. Finally, plants developed in similar growth conditions as described above for donor plants.

The number of AS as well as green and albino regenerants per spike was estimated and mean values for each line/ pre-treatment/medium combination was calculated from at least six replicates.

\section{Determination of ploidy level}

At least three samples consisting of approximately $1 \mathrm{~cm}^{3}$ of fresh leaf tissue were collected from each green regenerant and transferred to a glass Petri dish (on ice) for flow cytometry analysis. The same volume of fresh $(2 n=2 X=14)$ leaf tissue served as an external reference standard. Tissues were finely chopped with a razor blade in $500 \mu \mathrm{l}$ of Otto I solution (0.1 M citric acid, $0.5 \%$ Tween 20). Next, the suspension was filtered through a $42 \mu \mathrm{m}$ nylon mesh (Miltenyi Biotec $\mathrm{GmbH}$, Germany) into $5 \mathrm{ml}$ Eppendorf tubes and stained with $1 \mathrm{ml}$ of Otto II buffer $\left(0.4 \mathrm{M} \mathrm{Na}_{2} \mathrm{HPO}_{4} \cdot 12 \mathrm{H}_{2} \mathrm{O}\right)$ containing $2 \mathrm{mg} \mathrm{ml}^{-1} \beta$-mercaptoethanol and $2 \mu \mathrm{g} \mathrm{ml}^{-1}$ DAPI and incubated on ice in darkness for $15 \mathrm{~min}$ prior to analysis. Aliquots of stained nuclei $(50 \mu \mathrm{l})$ were mixed gently and ploidy was performed with a CyFlow Space flow cytometer (Sysmex Partec GmbH, Görlitz, Germany) equipped with a UV-led diode array. At least 5000 events measured per sample were considered a replicate.

\section{Statistical analyses}

The distribution of almost all analysed parameters was near to normal, skewed slightly towards the lower part of the 
frequency scale. However, as no procedure of data transformation resulted in a more normal distribution, the original data was used for further analysis. All data were examined by two-way analysis of variance (ANOVA), after which post hoc comparison was conducted using Duncan's multiple range test $(\mathrm{P} \leq 0.05)$. All statistical analyses were performed using STATISTICA version 13.1 package (Stat Soft Inc., USA, 2016). Raw data and detailed results of the statistical analyses will be provided on request.

Table 2 The sources of variance for mean microspore viability

\begin{tabular}{lll}
\hline Source of variation & Mean squares & $P$ \\
\hline Line & 3051 & $* * *$ \\
Treatment & 4891 & $* * *$ \\
Line $\times$ Treatment & 3107 & $* * *$ \\
\hline
\end{tabular}

The sources of variance for viability were as follows: 15 lines and four spike treatments and interaction between line and treatment

**** Significant at $\mathrm{P} \leq 0.001$

Table 3 The sources of variance for microspore viability and frequency of symmetric divisions in recalcitrant genotypes

\begin{tabular}{lll}
\hline Source of variation & \multicolumn{2}{l}{ Mean squares/P } \\
\cline { 2 - 3 } & Vitality & 2N Sym \\
\hline Treatment & $5186 / * * *$ & $521.6 / * * *$ \\
\hline
\end{tabular}

The sources of variance for microspore viability and frequency of symmetric divisions were as follows: 5 lines and four spike treatments and interaction between line and treatment

${ }^{* * * *}$ Significant at $\mathrm{P} \leq 0.001$

\section{Results}

\section{Effect of tiller pre-treatments on microspore vitality and symmetric divisions}

Based on microspores response, the rye lines were ranked into three categories: recalcitrant, moderate and responsive. When plotted against microspore viability, it can be seen that the moderate and responsive lines have significantly higher viability than the recalcitrant lines (Fig. 1b, c, S1). Microspores isolated from control tillers of the recalcitrant lines (lines 1, 2, 6, 9, 11, 12, 13, 15) had 3.5- and 3.9-fold lower vitality in comparison with responsive and moderate lines (lines 3, 4, 5, 7, 8, 10, 14), respectively (S1, S2).

Although microspore viability was significantly influenced by the genotype of donor plants (Table 2; Fig. 1b, c, $\mathrm{S} 1, \mathrm{~S} 2$ ), tiller pre-treatments (Control, GSH, MAN, GSH/ MAN, MAN/GSH) had a significant effect on the mean microspore vitality and the frequency of symmetric divisions leading to androgenic structure (AS) formation under in vitro conditions in all categories (Fig. 1, S3, S4). Glutathione had an effect on each genotype, but not to the same degree, or in the same way. Pre-treatments with glutathione alone (GSH) or in combination with mannitol (GSH/MAN and MAN/GSH) enhanced microspore viability up to the level of ca. 50\% viable microspores (S2) whereas MAN and its combination with GSH (MAN/GSH) increased the frequency of dividing microspores up to $12-14 \%$ for the moderate and responsive categories (S4). GSH/MAN and MAN/GSH tillers treatment usually increased (ca. 1.20-fold) microspore survivability after the isolation procedure and during the first days of in vitro culture (Fig. 1b). Combination of GSH and MAN improved microspore vitality in comparison with MAN on its own. Too high stress intensity (MAN) had a negative effect on microspore viability (S2) but simultaneously stimulated embryogenesis initiation (S4).

Table 4 The sources of variance for induction potential in microspore suspensions

\begin{tabular}{lc}
\hline Source of variation & Mean squares $/ P$ as per $105 \mathrm{mcs}$ \\
\hline Line & $27.65 / * * *$ \\
Treatment & $49.63 / * *$ \\
Medium & $40.58 / *$ \\
Line $\times$ Medium & $16.62 / *$ \\
Line $\times$ Treatment & $22.13 / * * *$ \\
Medium $\times$ Treatment & $5.02 / \mathrm{ns}$ \\
Line $\times$ Medium $\times$ Treatment & $17.83 / * *$ \\
\hline
\end{tabular}

The sources of variance for induction potential were as follows: 15 lines, four treatments, two types of induction media and interaction between line and medium, line and treatment, medium and treatment, line and medium and treatment. AS per $10^{5}$ mcs-effectiveness of androgenesis induction per one spike

$n s$ not significant

$*, * *, * * *$ Significant at $\mathrm{P} \leq 0.05, \mathrm{P} \leq 0.005$ and $\mathrm{P} \leq 0.001$, respectively 
A
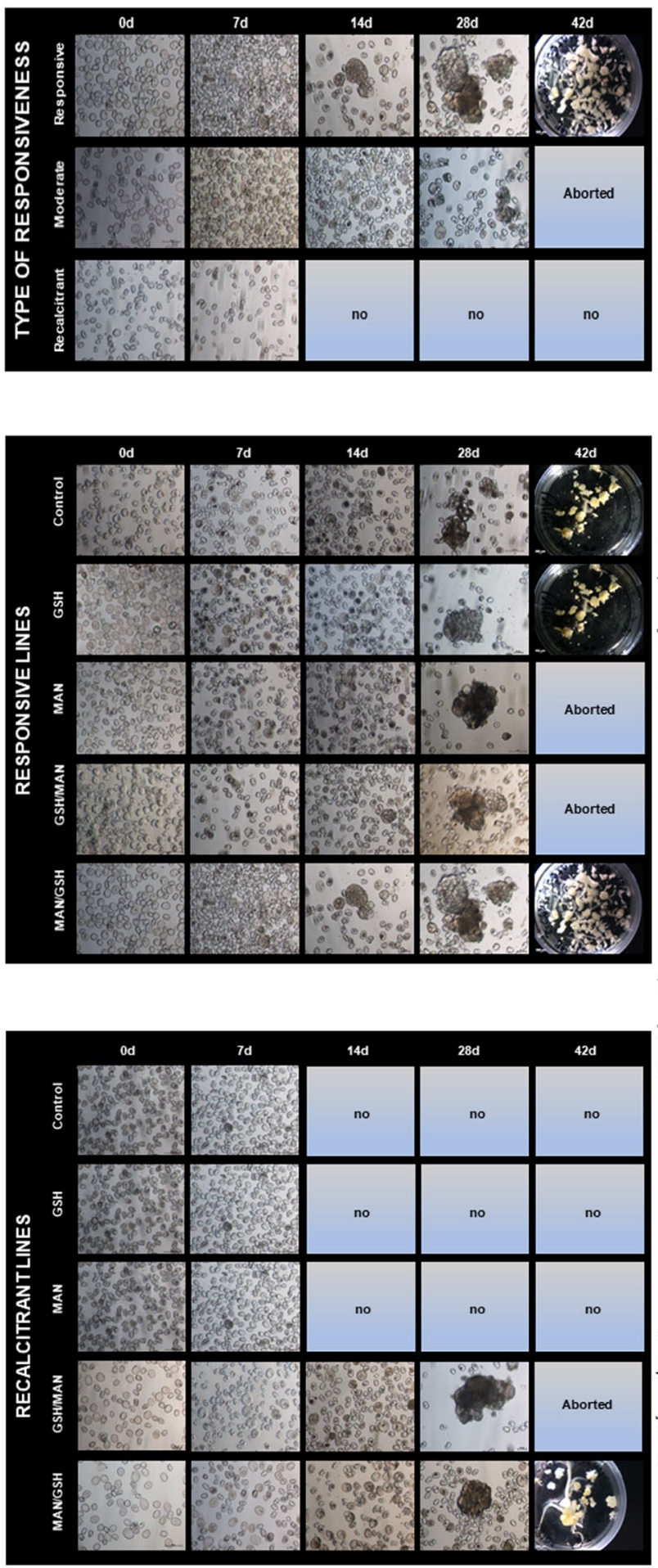

B

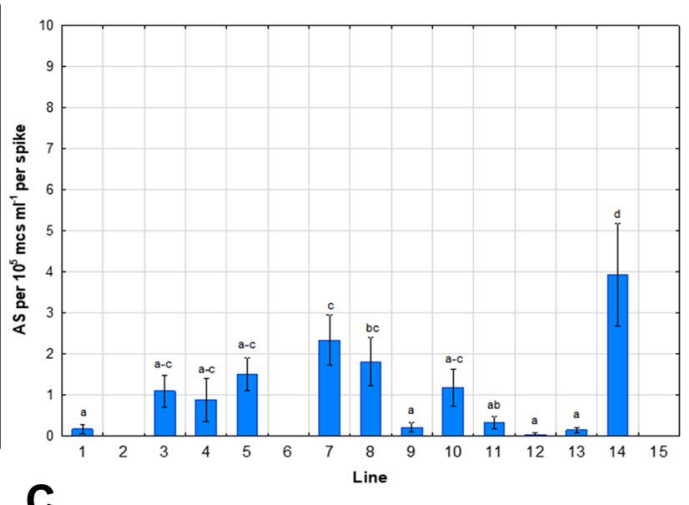

C
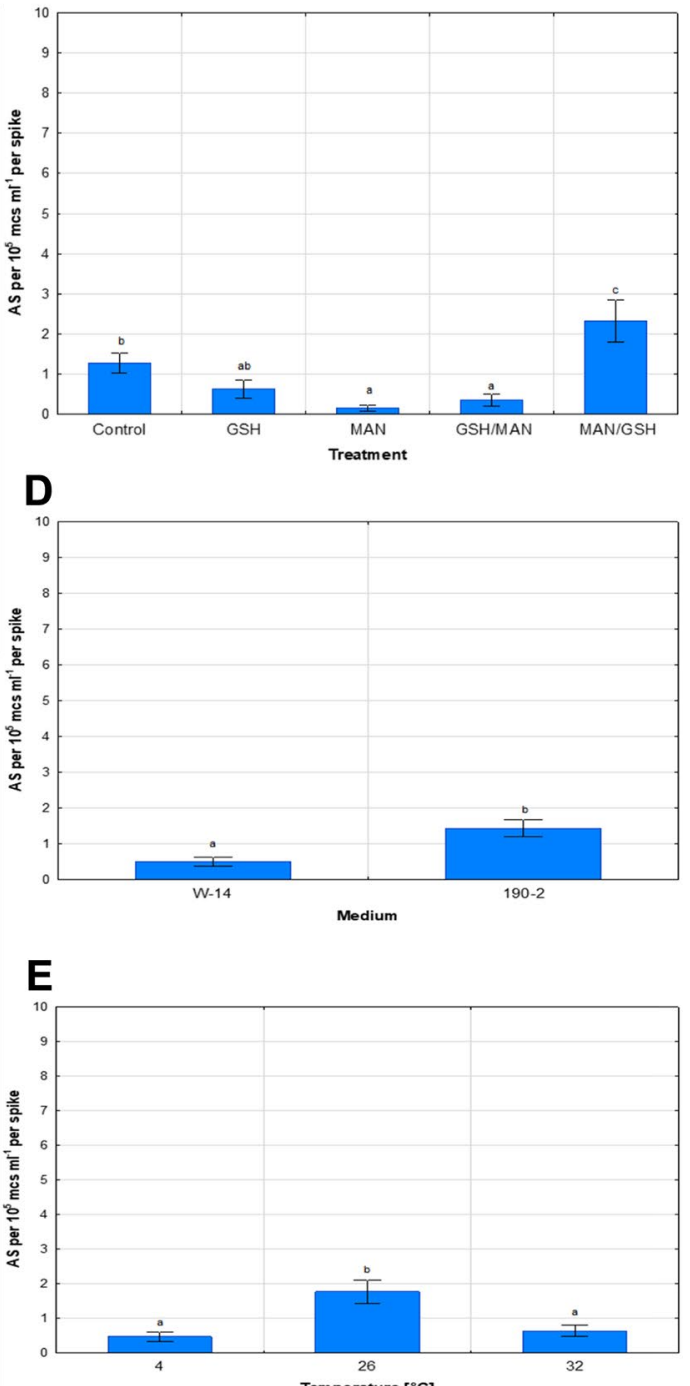

In the recalcitrant lines, microspore viability and frequency of symmetric divisions was significantly influenced by the tillers treatments (Table 3 ). Pre-treatments with glutathione alone (GSH) or in combination with mannitol (GSH/MAN and MAN/GSH) stimulated microspore viability 1.8-, 2.3- and 2.6-fold for GSH, GSH/MAN and MAN/
GSH, respectively (Fig. 1b). The order of treatments was crucial for the resistant lines. MAN/GSH was the only treatment able to increase microspore viability up to ca. 50\% viable cells (S2). Moreover, mannitol alone (MAN) or in combination with glutathione was the most effective in triggering symmetrical divisions. As a result, the frequency of 
4Fig. 2 The effect of tiller pre-treatments on androgenesis induction (on $0,7,14,28$ and 42d) in isolated microspore cultures of rye (Secale cereale L.). a Top board: The time course of microspore cultures with respect to the type of genotype. The 15 tested lines of rye are grouped into three categories of responsiveness: recalcitrant, moderate and responsive to androgenesis induction. Middle board: The time course of microspore cultures from responsive lines with respect to the tiller pre-treatment (Control, GSH, MAN, GSH/MAN or MAN/GSH). Bottom board: The time course of microspore cultures from recalcitrant lines with respect to the tiller pre-treatment (Control, GSH, MAN, GSH/MAN or MAN/GSH). Aborteddescribes suspension with embryos inhibited in development. Nodescribes non-embryogenic suspension. b Variation among 15 studied rye lines with respect to androgenesis induction response (AS per $10^{5} \mathrm{mcs} \mathrm{ml}^{-1}$ per spike) in microspore suspensions. c The effect of rye tiller pre-treatments (Control, GSH, MAN, GSH/MAN or MAN/ GSH) on the final effectiveness of androgenesis induction expressed as AS per $10^{5} \mathrm{mcs} \mathrm{ml}^{-1}$ per spike. d The effect of the induction medium on the final effectiveness of androgenesis induction (AS per $10^{5} \mathrm{mcs} \mathrm{ml}^{-1}$ per spike). e The effect of the temperature regime for culture incubation during induction on the final effectiveness of androgenesis induction (AS per $10^{5} \mathrm{mcs} \mathrm{ml}^{-1}$ per spike). Error bars b-e denote standard deviation of the mean (SD) between three biological replicates. Experimental points marked with the same letter do not differ according to Duncan's multiple range test $(\mathrm{P} \leq 0.05)$

embryogenic divisions was 4.6-5.3-fold higher (up to the level of ca. 20\%) in comparison with the control (Fig. 1b, S4).

\section{Androgenesis induction efficiency in isolated microspore cultures}

Androgenic responsiveness of microspore suspensions varied significantly among the 15 studied rye lines (S5), which were arranged by the level of susceptibility to embryo formation within three categories (responsive, moderate and recalcitrant) after 8 weeks of culture. The androgenic capacity was significantly influenced by the genotype of donor plants, tiller pre-treatment, type of medium and interactions between Line $\times$ Medium, Treatment $\times$ Medium and Line $\times$ Treatment $\times$ Medium (Table 4; Fig. 2a)

The studied rye lines presented a wide spectrum of responses regardless of medium type-the mean AS production per spike ranged from 0 to $4.6 \mathrm{AS}$ per $10^{5} \mathrm{mcs}$. The majority (11 lines) responded to the applied treatments and formed AS (eight lines under control, five under GSH, two under MAN and five under MAN/GSH; S5). The most effective among the tested treatments was MAN/GSH, where mean AS formation was almost twofold or 15-fold higher in comparison with control and MAN, respectively (Fig. 2c). 190-2 induction medium was significantly better than W-14 and yielded 2.5-fold higher effectiveness of AS formation (Fig. 2d). Embryogenesis efficiency on the tested media was genotype-specific and related to different responses to the type of medium - e.g. for lines 14 and 8 , the number of developed embryos increased 2.78-fold or 43.90-fold on
190-2 and W-14 medium, respectively (S5). Although such an impressive effect was observed for W-14 medium, the highest number of embryos was obtained on 190-2 medium (16.38 AS per $10^{5}$ mcs per spike; S5). Furthermore, on the 190-2 medium, under control, GSH and MAN/GSH pretreatments, all genotype categories produced AS (with the highest effectiveness obtained at $26^{\circ} \mathrm{C}$ for the responsive lines; S6). Therefore, from the applied temperature regimes, culture incubation at $26{ }^{\circ} \mathrm{C}$ was chosen as optimal (Fig. 2e).

Microscopic observations (conducted on 0, 7, 14, 28 and $42 \mathrm{~d}$ of in vitro culture) of microspore suspensions obtained from control spikes revealed that AS (at least to the stage of multicellular structures released from the exine) were derived only for responsive and moderately susceptible genotypes. However, properly developed AS around $5 \mathrm{~mm}$ in diameter were obtained only in the case of responsive lines. For moderately responsive genotypes, AS development was inhibited already after 4 weeks of culture at the stage of few-celled structure (Fig. 2a).

All applied combinations of spike treatments improved the process of androgenic embryo formation. Glutathione alone (GSH) or in combination with mannitol (GSH/MAN, MAN/GSH) was the most effective. Globular AS of responsive lines were formed after 28 days of culture in all variants of tiller pre-treatments. However, well-developed AS (bigger than $5 \mathrm{~mm}$ in diameter) were obtained only after three treatments: control, GSH and MAN/GSH. MAN in combination with GSH (MAN/GSH) accelerated embryo formation as multicellular globular structures were formed after just 14 days of in vitro culture in comparison with control, GSH, MAN and GSH/MAN (Fig. 2a).

Interestingly, in the case of recalcitrant lines, combined MAN and GSH treatment (in both variants) was the only one where AS were formed. The positive effect of GSH/MAN and MAN/GSH on globular embryo formation was observable after four weeks of culture. The effect persisted till the 42 nd day of culture, but only when MAN was applied for the first 14 days of the treatment. In these cultures, goodquality AS at the coleoptilar stage, able to germinate, were formed (Fig. 2a). However, green haploid/DHs regeneration was not observed.

\section{Androgenesis efficiency in anther cultures}

Androgenic responsiveness of the studied rye lines estimated by anther culture method varied significantly (at $\mathrm{P} \leq 0.05$ ) in respect of androgenic structure induction (AS per spike), total plant regeneration $\left(\mathrm{R}_{\text {Total }}\right.$ per spike and $\left.\mathrm{R}_{\text {Total }} 100 \mathrm{AS}^{-1}\right)$ and green plant regeneration ability $\left(R_{\text {Green }}\right.$ per spike and $\mathrm{R}_{\text {Green }} 100 \mathrm{AS}^{-1}$ ).

The capacity for androgenesis induction (AS per spike) among the 15 studied rye lines was influenced by the 


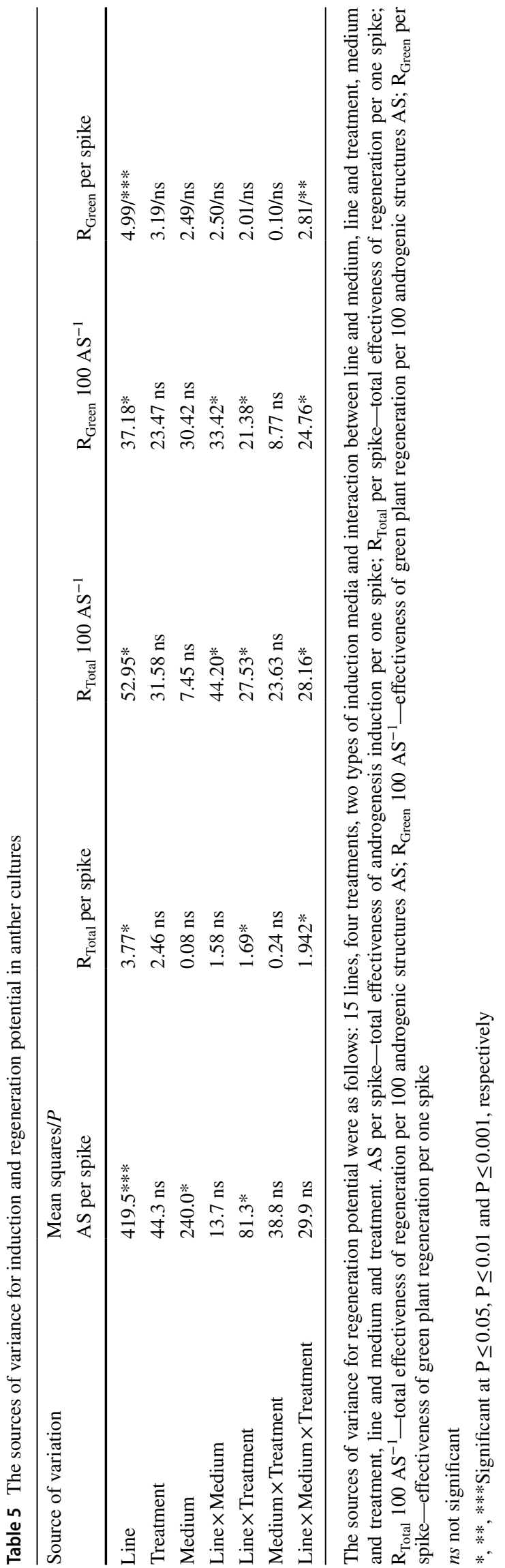

genotype of donor plants, type of medium and interactions between Line $\times$ Treatment (Table 5; Fig. 3a-c, S7).

The positive effect of exogenously applied GSH on its effectiveness was observed only at the induction phase and depended on the genotype (Fig. 3b, S7, S8) and on the type of induction medium-e.g. for line 8, mean AS per spike increased 2.08-fold on $\mathrm{W}-14$ medium when tillers were GSH-treated (S8).

The final androgenesis induction effectiveness averaged for the 15 lines of rye presented a wide spectrum of responses-with the mean number of AS per spike ranging from 0 to 21.3 (Fig. 3c) and the mean total regeneration ability from 4 to $30 \mathrm{R}_{\text {Total }}$ per spike. Although the type of tiller pre-treatment and the induction medium did not significantly influence the regeneration, interactions between Line $\times$ Medium, Line $\times$ Treatment and Line $\times$ Medium $\times$ Treatment significantly influenced four regeneration parameters: $R_{\text {Total }}$ per spike, $R_{\text {Total }} 100 \mathrm{AS}^{-1}$, $\mathrm{R}_{\text {Green }}$ per spike and $\mathrm{R}_{\text {Green }} 100 \mathrm{AS}^{-1}$ (Table 5).

The average androgenesis induction efficiency for the most responsive lines $(7,8,12,14)$ was almost threefold higher in comparison to the moderately responsive lines (1, $4,10,11)$ and 14 -fold higher in comparison to the recalcitrant ones $(2,3,5,6,9,13,15)$. The mean parameter AS per spike for those groups was 11,3 and 0.7 , respectively. For all three groups, the most important was the effect of the interaction between Line $\times$ Treatment.

Plant regeneration was achieved for four rye lines $(4,11$, $12,14)$ with the effectiveness ranging from 0.3 to $3.2 \mathrm{R}_{\text {Green }}$ per spike and from 0.3 to $6.0 \mathrm{R}_{\text {Total }}$ per spike (S7). In total, 12 green plants were obtained, with the highest number of regenerants obtained for line 11 (Fig. 3d; S7). In the case of this line, MAN was the only treatment which resulted in $5.60 \mathrm{R}_{\text {Green }}$ per spike regenerated from AS induced on 190-2 medium (S7). The majority (55\%) of regenerants of line 11 (three plants), line 12 (one plant) and line 14 (three plants) had diploid (2n) number of chromosomes, which characterizes double haploids (DHs). The remaining $45 \%$ of green regenerants represented haploids (three plants obtained from lines no. 11, 12 and 14) and tetraploids (18\%, two plants obtained from line 11). Exemplary cytograms and phenotypes of regenerants are shown in Fig. 3e.

\section{Androgenesis efficiency: anther cultures vs microspore cultures}

Androgenic responsiveness varied significantly among the 15 studied rye lines (S5-S8) in both types of cultures: anther cultures (AC) and microspore suspensions (MC). The genotype of donor plants, type of medium and interactions between Line $\times$ Treatment $\times$ Medium significantly influenced the androgenic capacity in $\mathrm{AC}$ and $\mathrm{MC}$. 
In general, higher mean effectiveness of androgenesis induction was obtained in anther cultures in all categories of genotypes with different responsiveness to that process. Low temperature (control) and GSH were the most effective for both AC and MC (Table 6). The observed tendency to increase the final effectiveness in $\mathrm{MC}$ of recalcitrant lines (2.4-fold on W-14 medium; S7) resulted from GSH effect on microspores viability (ca. twofold; S7), whereas MAN seemed to stimulate regeneration ability $\left(\mathrm{R}_{\text {Total }}\right.$ per spike and $\mathrm{R}_{\text {Green }}$ per spike) in recalcitrant lines $(\mathrm{S} 7, \mathrm{~S} 8)$.

\section{Discussion}

Research focused on optimization of rye (S. cereale L.) DH production protocols was performed in several national research centers without spectacular success (Zimny 1993; Immonen and Anttila 1996a, b; Szarejko 2003). The major problem lies in genotype dependence of cross-pollinated rye with regard to tissue culture response. However, in vitro biotechnological methods improving the regeneration phase could accelerate the breeding of rye (Targońska et al. 2013). The use of self-pollinated rye, although troublesome, could be more beneficial for tissue culture being a part of DH technology (Immonen and Tenhola-Roininen 2003). As selfpollination leads to independent homozygous lines, variation is structured in the form of numerous true breeding cultivars handled by the farmer. Therefore, in our research we used both cross-pollinated lines and lines expressing selfcompatibility genes (no. 8, 9, 10,11, 12). A universal rye anther/isolated microspore culture protocol for self- or crosspollinated rye will be valuable in hybrid rye production of homozygous DH lines facilitating the traditional breeding process. The DH method will make rye breeding economical and efficient, and the restrictions of self-incompatibility will be overcome.

As ROS generation, cell tolerance to ROS accumulation and antioxidative defence efficiency influence the effectiveness of in vitro anther cultures of triticale (Żur et al. 2014), the stress intensity has to be balanced. The ability to sustain antioxidative activity (enzymatic and non-enzymatic) under cold stress in the dark was proposed as one of the most important conditions/requirements for high effectiveness of androgenesis induction in triticale. Genetic control of cell tolerance to oxidative stress could be environmentally modified e.g. by a glutathione treatment of tillers. Enhanced by exogenously applied GSH, antioxidative defence promotes androgenic embryo development (Żur et al, 2019).

We proposed a modified 3-week pre-treatment of tillers-a combination of low temperature (Control), osmotic stress (MAN) and/or GSH. The effect of those treatments on microspore vitality and their ability to divide symmetrically (as evidence of androgenesis initiation) was analysed in 15 Polish rye lines. Cytological studies in the earliest stages of androgenesis induction on such a broad spectrum of rye genotypes and treatment modifications have not been performed or published so far.

Prolonged spike pre-treatments with MAN and GSH applied independently or in different configurations affected microspore vitality and the frequency of symmetrical divisions. Pre-treatments with glutathione alone (GSH) or in combination with mannitol (GSH/MAN and MAN/GSH) enhanced microspore viability up to the level of ca. $50 \%$ viable and up to $12-14 \%$ dividing microspores for the moderate and responsive categories. For recalcitrant lines, MAN/GSH was the only treatment able to increase microspore viability up to ca. 50\% viable cells. The efficacy of GSH is enhanced probably by its intrinsic acidity (pH 5.4 in HS) at $0.30 \mathrm{mM} \mathrm{GSH}$. Low $\mathrm{pH}$ probably influences the relatively high activity of invertase-over a broad range of $\mathrm{pH}$ (3.5-5.5)—catalyses the hydrolysis of sucrose, which triggers rye microspore viability and development towards embryogenesis for both AC and MC cultures. Carbohydrate starvation with MAN treatment at $4{ }^{\circ} \mathrm{C}$ enhanced cell cycle progression to a symmetric division and finally to $\mathrm{DH}$ plants regeneration, especially in recalcitrant lines.

We found that the balance between divided and vital microspores is of high importance. Moreover, an opposite effect among those two cytological parameters was observed. In the case of recalcitrant lines, the best efficiency of ME was obtained in suspensions with ca. 0.43 ratio between dividing and vital microspores. Microspore suspensions with too high ( 0.57 or 0.85 for GSH/MAN and MAN, respectively) or too low ( 0.15 or 0.24 for GSH and Control, respectively) proportion of dividing microspores failed to enter embryogenesis. It could be supposed that the optimal frequency of dividing microspores is between 25 and 50\%. When normal cells grown in a dish are crowded by neighbours on all sides, they will no longer divide and will undergo programmed cell death (e.g. due to DNA damage).

The role of proper pre-treatments in androgenesis was often emphasized as a prerequisite for embryogenesis initiation. Effective induction of androgenesis in response to low temperature was observed in barley (Huang and Sunderland 1982; Devaux et al. 1993), rice (Genovesi and Magill 1979; Chen et al. 1991), wheat (Gustafson et al. 1995; Hu and Kasha 1999), corn (Genovesi 1990; Pescitelli et al. 1994), oats, triticale, flax, and tobacco (citations from Shariatpanahi et al. 2006). The positive effect of low temperature is probably based on the slowing down of degradation processes and microspore protection from the effects of toxic compounds released from dying cells (Duncan and Heberle-Bors 
A

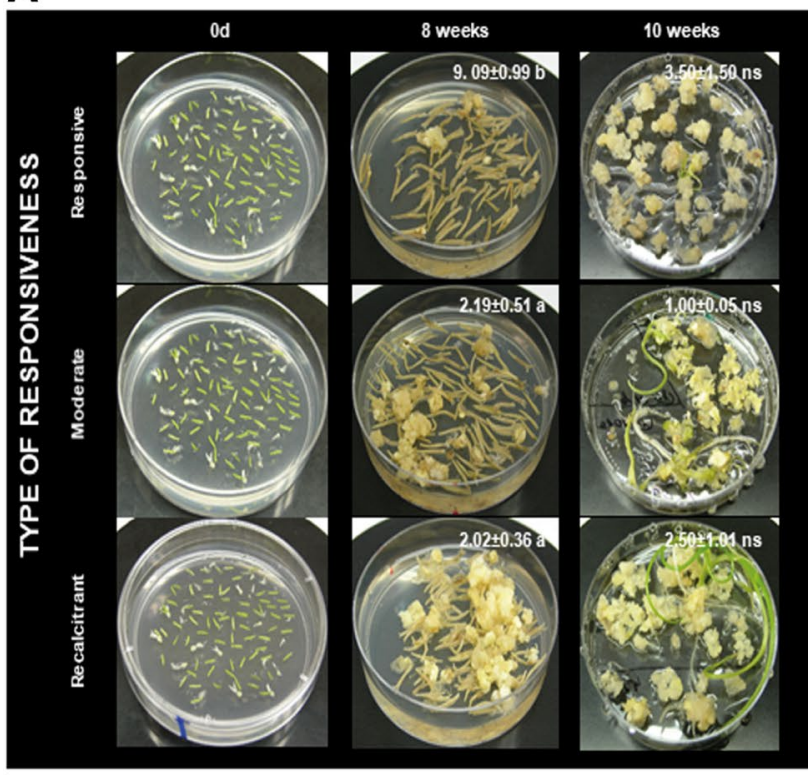

B

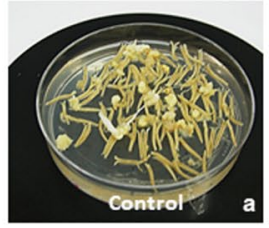

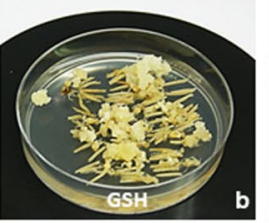

E
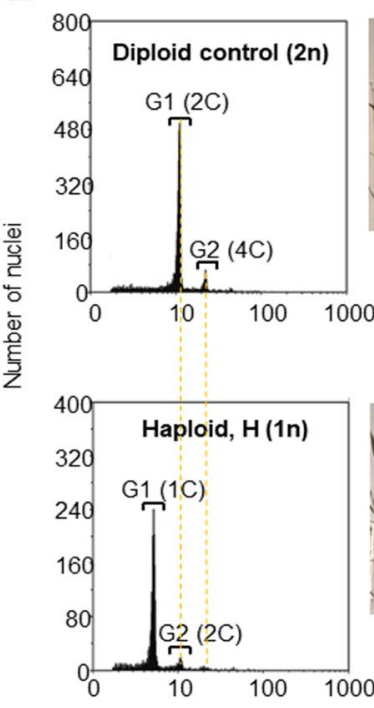

C

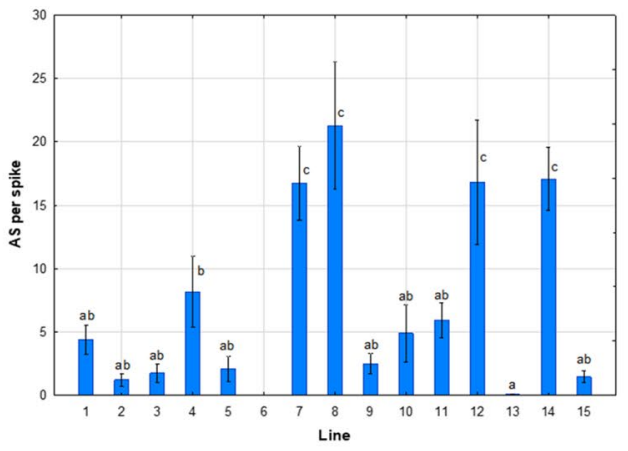

D

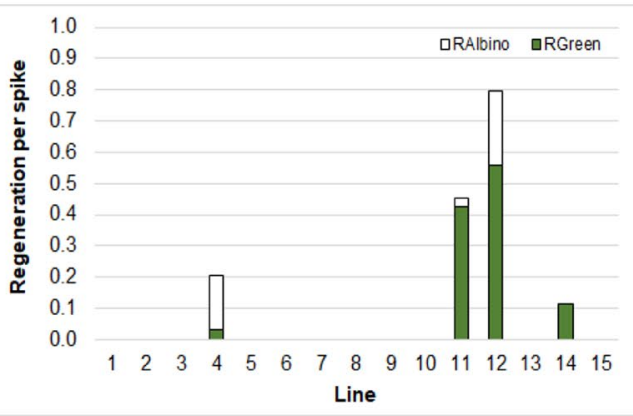

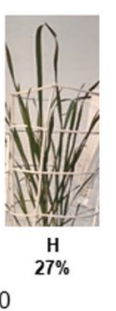
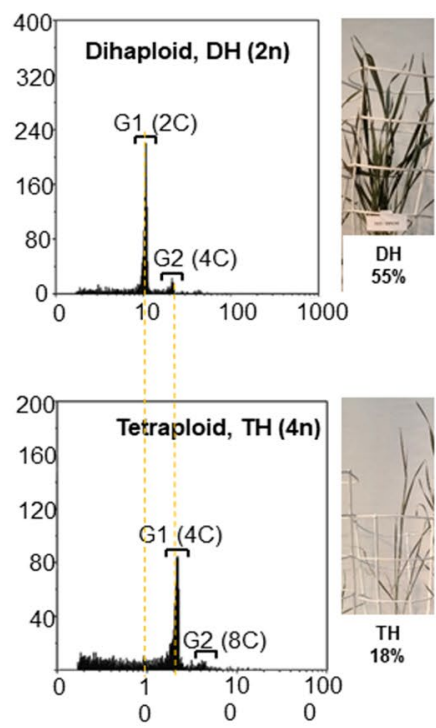

Relative DNA content

1976). Low temperature synchronizes microspore development and breaks cytoplasmic connections between microspores and tapetum. Disconnected from anther sporophytic tissue, isolated microspores could immediately receive signals to change their developmental pathway. Low temperature also causes 'starvation stress', which is another factor 
4Fig. 3 The effect of tiller pre-treatments on androgenesis induction (0d, after 8 weeks) and regeneration (after 10 weeks) in anther cultures of rye (Secale cereale L.). a The time course of anther cultures with respect to the type of genotype. The 15 tested lines of rye are grouped into three categories of responsiveness: recalcitrant, moderate and responsive to androgenesis induction. Right corner of the photo: means \pm SD between three biological replicates. Experimental points marked with the same letter do not differ according to Duncan's multiple range test $(\mathrm{P} \leq 0.05)$. b The effect of tiller pre-treatments (Control, GSH, MAN) on the time course of anther cultures after 10 weeks. c Variation among 15 studied rye lines with respect to androgenesis induction response (AS per spike) in anther cultures. Error bars denote SD between three biological replicates. Experimental points marked with the same letter do not differ according to Duncan's multiple range test $(\mathrm{P} \leq 0.05)$. d Variation among 15 studied rye lines with respect to regeneration (per spike) of androgenic structures in anther cultures. Average regeneration ability. Presented data for each genotype are the means of seven replicates $\pm S D$. $R_{\text {Green }}$ total number of green plants per spike. $\mathrm{R}_{\text {Albino }}$-total number of albino plants per spike. e Flow cytometer results from green regenerated plants. Reprehensive histograms of nuclear DNA contents (relative fluorescence intensities of DAPI) obtained from the analysis of diploid plant serving as a control and dihaploid $(\mathrm{DH})$, haploid $(\mathrm{H})$ and tetraploid plants; $\mathrm{x}$-axis shows DNA content (relative fluorescence on $\log 3$ scale) and y-axis - the number of measured particles. Peaks correspond to nuclei in G1 and G2 stages. C-value is indicated for each peak. The space between both peaks is considered to represent $S$ phase nuclei. Control (diploid; $2 \mathrm{n}$; number of chromosomes), haploid $(\mathrm{H}, 1 \mathrm{n})$, doubled haploid $(\mathrm{DH}, 2 \mathrm{n})$, tetraploid $(\mathrm{TH}, 4 \mathrm{n})$. Exemplary cytograms and phenotypes of regenerants

for initiating androgenesis (Sunderland and Xu 1982). It is known that spike treatment with low temperature $\left(4^{\circ} \mathrm{C}\right)$ may increase microspore resistance to stress associated with isolation and transfer to in vitro conditions (Żur et al. 2014, 2019) and also improve the ability of cells to divide in some cereals.

In our work, the effect of tiller pre-treatments with low temperature (Control, $4{ }^{\circ} \mathrm{C}$ ) and MAN and/or GSH in relation to androgenesis induction was more prominent in microspore than in anther cultures.

The positive effect of mannitol (as a substance not metabolized by plant cells and triggering microspores to divide) on rye androgenesis effectiveness was partially confirmed by Rakoczy-Trojanowska et al. (1996), Guo and Pulli (2000), Ma et al. (2004) and Tenhola-Roininen et al. (2005). However, low temperature spike pre-treatment $\left(4^{\circ} \mathrm{C}\right)$ and osmotic stress (anther pre-culture with $0.3 \mathrm{M}$ mannitol for $24 \mathrm{~h}$ ), reported as the most promising, did not work in our study. Therefore, mannitol in the concentration of $0.7 \mathrm{~mol} \mathrm{l}^{-1}$ resulting in high osmotic potential (ca. $70 \mathrm{mOsm} \mathrm{l}^{-1}$ ) and starvation stress were used for at least 7-day-long tiller pretreatment. The applied MAN treatment reduced microspore viability, but enhanced their symmetrical divisions, especially in the group of recalcitrant lines ( $>$ fivefold). Although the final induction effectiveness was 71-fold lower than for spring rye Florida 401 described by Guo and Pulli (2000), the beneficial effect of MAN in our conditions and with the tested Polish winter rye lines was optimistic. It was probably the effect of MAN-dependent enhanced generation of ROS, molecules involved in signal transduction and initiation of defense response.

The positive effect of GSH on rye microspore embryogenesis could be explained by enhanced microspore vitality observed on the isolation day. This tripeptide ( $\gamma$-glutamylcysteinyl-glycine) is the major low molecular weight antioxidant which regulates redox signalling, controls gene expression and contributes to plant cell survival under stress conditions (Foyer et al. 2001; Maughan and Foyer 2006; Zaffagnini et al. 2012a, b). The reduced form of glutathione (GSH), which detoxifies ROS through the ascorbate-glutathione cycle, protects plant cells from oxidative damage (Foyer and Noctor 2009, 2011; Noctor et al. 2012; Zechmann 2014). Exogenously applied GSH plays an important role in protecting microspores from harmful effects of stress e.g. low temperature (Payton et al. 2001; Żur et al. 2019). We suppose that an external source of the high level of GSH allows for its rapid accumulation within nuclei, which protects DNA and redox-sensitive nuclear proteins from oxidation. On the other hand, if the redox balance of nuclei is altered, DNA damage could induce cell death (Diaz-Vivancos et al. 2010). High GSH level in the nucleus also allows the G1 to $S$ phase transition in the plant cell cycle (Vernoux et al. 2000) and finally cell proliferation (Menon et al. 2003).

Taking this into account, we suppose that the protection by GSH allows genes responsible for embryogenesis to be expressed and androgenic embryos of rye to finally be formed.
Table 6 The influence of spike pre-treatment on mean androgenesis induction effectiveness in anther (AS per spike) and microspore (AS per $10^{5} \mathrm{mcs} \mathrm{ml}^{-1}$ per spike) cultures

\begin{tabular}{|c|c|c|c|c|c|c|}
\hline \multirow[t]{3}{*}{ Type of responsiveness } & \multicolumn{6}{|c|}{ Spike pre-treatment } \\
\hline & \multicolumn{2}{|c|}{ Control } & \multicolumn{2}{|l|}{ GSH } & \multicolumn{2}{|c|}{ MAN } \\
\hline & $\mathrm{AC}$ & MC & $\mathrm{AC}$ & $\mathrm{MC}$ & $\mathrm{AC}$ & MC \\
\hline Responsive & 12.2 & 4.8 & 12.7 & 0.5 & 8.1 & 0.6 \\
\hline Moderate & 3.6 & 2.7 & 10.1 & 3.0 & 3.7 & 1.0 \\
\hline Recalcitrant & 2.7 & 0.3 & 0.9 & 0.4 & 1.2 & - \\
\hline
\end{tabular}

Control low temperature spike treatment in Hoagland medium, GSH low temperature spike treatment in solution with GSH, MAN low temperature spike treatment in mannitol, $A S$ androgenic structures, $A C$ anther cultures, $M C$ microspore cultures 
Despite increased cell viability and the number of embryogenic microspores caused by exogenously applied GSH, the final effectiveness of haploid/DH plant production was insufficient. The lack of coincidence between those parameters resulted from a stable increase in LMW antioxidant activity. Only rapid endogenous GSH elevation, caused by the interaction between the genotype and tiller pre-treatment with exogenous GSH, could induce and sustain microspore viability associated with an increased number of embryogenic microspores in responsive lines. In the case of recalcitrant lines, the long-term application of GSH is the most effective, at least at the induction phase. The supplied GSH supports inefficient antioxidative system. However, excessive ROS elimination can suppress the signal necessary for microspore reprogramming, and reduced environment during in vitro culture can inhibit ELS development or impair their ability to regenerate into plants (Żur et al. 2019). Therefore, the balance between oxidative stress and antioxidants is the firstalthough not the only-prerequisite for effective microspore embryogenesis initiation.

High level of exogenous GSH triggered rye embryogenesis and green plant regeneration in our research. However, the effect of GSH depended on the presence of MAN. Interestingly, the type of combination and the order of stress type were important for proper AS formation (in $\mathrm{MC}$ and $\mathrm{AC}$ ) and plant regeneration (in AC). The treatment with MAN/ GSH was the only one which resulted in AS germination in MC. The mean AS formation was almost twofold or 15-fold higher in comparison with the control and MAN, respectively. GSH together with MAN (MAN/GSH) accelerated globular structure formation in comparison with other treatments. Finally, after 14 days of in vitro culture, multicellular structures were formed, then after 42 days transited into AS at the coleoptilar stage.

Although spike pre-treatment determined the effectiveness of androgenesis, the genotype of donor plants and type of medium could cause some limitations. Despite this, 13 lines (from all 15 lines studied) responded positively and formed AS. The impact of GSH on androgenesis effectiveness was observed only at the induction phase and depended on the genotype and the type of induction medium within the responsive category. In general, cultures on 190-2 induction medium at $26{ }^{\circ} \mathrm{C}$ were significantly better than on W-14. The interaction between some variables such as line and/or medium and/or treatment was important in anther cultures for the effectiveness of ME induction and plant regeneration. The impact of genotype on androgenesis induction and plant regeneration effectiveness was often described (Sozinov et al. 1981; Rogalska and Mikulski 1995; Immonen and Anttila 1996a; Rakoczy-Trojanowska et al. 1997; ŚlusarkiewiczJarzina and Ponitka 1997; Marciniak 1998; Wędzony et al. 1999).
Similarly, the process of nuclear DNA duplication (correlated with the ploidy level; Ochatt 2008) without colchicine treatment is also known in rye regenerants (Immonen and Tenhola-Roininen 2003). Low temperature together with GSH or MAN seems to increase the proportion of DH plants. Although in the present work, flow cytometry showed that spontaneously formed diploids (doubled haploids, DHs) were present at a relatively high percentage of $55 \%$, the mechanism of diploidization in the case of rye microspores was not studied and needs further examination.

The present study is the first report evaluating a wide range of rye genotypes in both $\mathrm{AC}$ and $\mathrm{MC}$ techniques. Relatively high effectiveness of androgenesis induction shows that the developed protocol with GSH and/or MAN tiller pre-treatments overcomes genotypic variation. We could also propose the proportion between dividing and vital microspores as a possible cytological marker of plant responsiveness to androgenesis induction treatment. Moreover, high frequency of spontaneous diploidization suggests that optimized protocols for AC and MC could be effectively integrated into conventional rye breeding programmes in the coming future.

Acknowledgements The research was performed in the frame of the national research project financed by the Basic Research for Biological Progress in Plant Production Program of the Ministry of Agriculture and Rural Development (No. 84): 'Identification of factors determining the efficiency of doubled haploids production in rye (S. cereale $\mathrm{L}$.) through androgenesis and distant crosses'.

Author contributions $\mathrm{KZ}$ conducted experiments and contributed to statistical analyses. MK, KJ, PK, AN, JM conducted experiments. ES measured ploidy level. IŻ conducted experiments and participated in writing the manuscript. ED conceived and designed the research, conducted experiments and wrote the manuscript. All authors read and approved the manuscript.

Open Access This article is licensed under a Creative Commons Attribution 4.0 International License, which permits use, sharing, adaptation, distribution and reproduction in any medium or format, as long as you give appropriate credit to the original author(s) and the source, provide a link to the Creative Commons licence, and indicate if changes were made. The images or other third party material in this article are included in the article's Creative Commons licence, unless indicated otherwise in a credit line to the material. If material is not included in the article's Creative Commons licence and your intended use is not permitted by statutory regulation or exceeds the permitted use, you will need to obtain permission directly from the copyright holder. To view a copy of this licence, visit http://creativecommons.org/licenses/by/4.0/.

\section{References}

Asif M, Eudes F, Goyal A, Amundsen E, Randhawa H, Spaner D (2013) Organelle antioxidants improve microspore embryogenesis in wheat and triticale. Vitro Cell Dev Biol 49:489-497. https ://doi.org/10.1007/s11627-013-9514-z 
Chen JS, Wei C, Marshall MR (1991) Inhibition mechanism of kojic acid on polyphenol oxidase. J Agric Food Chem 39(11):1897-1901

Chu CC (1978) The N6 medium and its applications to anther culture of cereal crops. Proceedings of symposium on plant tissue culture. Science Press, Beijing, pp 43-50

Chuang CC, Ouyang TW, Chia H, Chou SM, Ching CK (1978) A set of potato media for wheat anther culture. Proc Symp on plant tissue culture. Science Press, Peking, pp 51-56

Cistué L, Batlle RF, Echávarri B (2009) Improvements in the production of doubled haploids in durum wheat (Triticum turgidum L.) through isolated microspore culture. Plant Cell Rep 28:727-735. https://doi.org/10.1007/s00299-009-0690-6

Custers JBM, Cordewener JHG, Nöllen Y, Dons HJM, Van Lookeren Campagne MM (1994) Temperature controls both gametophytic and sporophytic development in microspore cultures of Brassica napus. Plant Cell Rep 13:267-271. https://doi.org/10.1007/BF002 33317

Daniel G (1993) Anther culture in rye: improved plant regeneration using modified MS-media. Plant Breed 110:259-261. https://doi. org/10.1111/j.1439-0523.1993.tb00587.x

Deimling S, Flehinghaus-Roux T, Röber F, Schechert S, Roux R, Geiger HH (1994) Doubled haploid production-now reproducible in rye. In: Abstracts VIIIth international congress of plant tissue and cell culture, June 12-17, Firenze, p 95

Devaux F, Sorel Y, Kerdiles JF (1993) Simple measurement of fiber dispersion and of chirp parameter of intensity modulated light emitter. J Lightwave Technol 11(12):1937-1940. https://doi. org/10.1109/50.257953

Díaz-Vivancos P, Barba-Espín G, Clemente-Moreno JM, Hernández JA (2010) Characterization of the antioxidant system during the vegetative development of pea plants. Biol Plant 54(1):76-82. https://doi.org/10.1007/s10535-010-0011-5

Duncan EJ, Heberle-Bors E (1976) Effect of temperature shock on nuclear phenomena in microspores of Nicotiana tabacum and consequently on plantlet production. Protoplasma 90:173-177. https://doi.org/10.1007/BF01276486

Ferrie AM, Caswell KL (2011) Isolated microspore culture techniques and recent progress for haploid and doubled haploid plant production. Plant Cell Tiss Org 104:301-309. https://doi.org/10.1007/ s11240-010-9800-y

Flehinghaus T, Deimling S, Geiger HH (1991) Methodogical improvements in rye anther culture. Plant Cell Rep 10:397-400. https:// doi.org/10.1007/BF00232610

Flehinghaus-Roux T, Deimling S, Geiger HH (1995) Anther culture ability in Secale cereale L. Plant Breed 114:259-261. https://doi. org/10.1111/j.1439-0523.1995.tb00807.x

Foyer CH, Noctor G (2009) Redox regulation and photosynthetic organisms: signaling, acclimation and practical implications. Antioxid Redox Signal 11:861-905. https://doi.org/10.1089/ ars.2008.2177

Foyer CH, Noctor G (2011) Ascorbate and glutathione: the heart of the redox hub. Plant Physiol 155:2-18. https://doi.org/10.1104/ pp. 110.167569

Foyer CH, Theodoulou FL, Delrot S (2001) The functions of inter- and intracellular glutathione transport systems in plants. Trends Plant Sci 6:486-492. https://doi.org/10.1016/S1360-1385(01)02086-6

Genovesi AD (1990) Maize (Zea mays L.): In vitro production of haploids. In: Bajaj YPS (ed.) Biotechnology in agriculture and forestry 12-haploids in crop improvement I, pp. 176-203. Springer, Berlin. doi: 10.1007/978-3-642-61499-6_7.

Genovesi AD, Magill CW (1979) Improved rate of callus and green plant production from rice anther culture following cold shock 1. Crop Sci 19(5):662-664. https://doi.org/10.2135/cropsci197 $9.0011183 \times 001900050030 \mathrm{x}$
Guo YD, Pulli S (2000) Isolated microspore culture and plant regeneration in rye (Secale cereale L.). Plant Cell Rep 19(9):875-880. https://doi.org/10.1007/s002990000194

Gustafson V, Baenziger PS, Wright MS, Stroup WW, Yen Y (1995) Isolated wheat microspore culture. Plant Cell Tiss Org 42:207213. https://doi.org/10.1007/BF00034239

Heslop-Harrison J, Heslop-Harrison Y (1970) Evaluation of pollen viability by enzymatically induced fluorescence: intracellular hydrolysis of fluorescein diacetate. Stain Technol 45(3):115-120. https://doi.org/10.3109/10520297009085351

$\mathrm{Hu}$ T, Kasha KJ (1999) A cytological study of pretreatments used to improve isolated microspore cultures of wheat (Triticum aestivum L.) cv. Chris. Genome 42(3):432-441. https://doi.org/10.1139/ g99-002

Huang B, Sunderland N (1982) Temperature-stress pretreatment in barley anther culture. Ann Bot Lond 49(1):77-88. https://doi. org/10.1093/oxfordjournals.aob.a086232

Immonen S (1999) Androgenetic green plants from winter rye, Secale cereale L., of diverse origin. Plant Breed 118:319-322. https:// doi.org/10.1046/j.1439-0523.1999.00381.x

Immonen S, Anttila H (1996a) Success in anther culture of rye. In: Proceedings of EUCARPIA international symposium on rye breeding and genetics. Vortr Pflanzenzüchtg vol 35, pp 237-244.

Immonen S, Anttila H (1996b) Cold pretreatment to enhance green plant regeneration from rye anther culture. Plant Cell Tiss Org 57:121-127. https://doi.org/10.1023/A:1006381516632

Immonen S, Tenhola-Roininen T (2003) Protocol for rye anther culture. In: Maluszynski M, Kasha KJ, Forster BP, Szarejko I (eds) Doubled haploid production in crop plants: a manual. Kluwer Academic Publishers, Dordrecht, pp 141-150

Lundqvist A (1956) Self-incompatibility in rye. I Genetic control in the diploid. Hereditas 42:293-348

Ma R, Guo YD, Pulli S (2004) Comparison of anther and microspore culture in the embryogenesis and regeneration of rye, Secale cereale. Plant Cell Tiss Org 76:147-157. https://doi.org/10.1023/ B:TICU.0000007294.68389.ed

Marciniak K, Banaszak Z, Wędzony M (1998) Effect of genotype, medium and sugar on triticale ( $\times$ Triticosecale Wittm) anther culture response. Cereal Res Commun 26(2):145-151

Maughan S, Foyer CH (2006) Engineering and genetic approaches to modulating the glutathione network in plants. Physiol Plant 126:382-397. https://doi.org/10.1111/j.1399-3054.2006.00684.x

Menon SG, Sarsour EH, Spitz DR, Higashikubo R, Sturm M, Zhang H, Goswami PC (2003) Redox regulation of the G1 to S phase transition in the mouse embryo fibroblast cell cycle. Cancer Res 63:2109-2117

Noctor G, Mhamdi A, Chaouch S, Han Y, Neukermans J, MarquezGarcia B, Queval G, Foyer CH (2012) Glutathione in plants: an integrated overview. Plant Cell Environ 35:454-484. https://doi. org/10.1111/j.1365-3040.2011.02400.x

Ochatt SJ (2008) Flow cytometry in plant breeding. Cytometry Part A 73(7):581-598. https://doi.org/10.1002/cyto.a.20562

Ouyang JW, Jia SE, Zhang C, Chen X, Feng G (1989) A new synthetic medium (W14) for wheat anther culture. Annual Report, 91-92. Institute of Genetics, Academia Sinica, Beijing

Payton P, Webb R, Kornyeyev D, Allen R, Holaday AS (2001) Protecting cotton photosynthesis during moderate chilling at high light intensity by increasing chloroplastic antioxidant enzyme activity. J Exp Bot 52(365):2345-2354. https://doi.org/10.1093/jexbo $\mathrm{t} / 52.365 .2345$

Pescitelli SM, JohnsonJ CD, Petolino F (1994) Isolated microspore culture of maize. In: Bajaj Y.P.S. (ed) Maize Biotechnology in agriculture and forestry, vol 25. Springer, Berlin, pp 186-200. doi: 10.1007/978-3-642-57968-4_13. 
Rakoczy-Trojanowska M, Kwaśniak A, Malepszy S (1996) Factors influencing viability and sporophytic development in vitro of rye (Secale cereale L.) microspores. Vortr Pflanzenzücht 35:256-257

Rakoczy-Trojanowska M, Śmiech M, Malepszy S (1997) The influence of genotype and medium on rye (Secale cereale L.) anther culture. Plant Cell Tiss Org 48:15-21. https://doi.org/10.1023/A:10057 92912316

Rogalska S, Mikulski W (1995) Androgeneza u pszenżyta (× Triticosecale Witt.). Biuletyn Instytutu Hodowli i Aklimatyzacji Roślin. 195-196:21-31

Shariatpanahi ME, Bal U, Heberle-Bors E, Touraev A (2006) Stresses applied for the re-programming of plant microspores towards in vitro embryogenesis. Physiol Plant 127(4):519-534. https:// doi.org/10.1111/j.1399-3054.2006.00675.x

Ślusarkiewicz-Jarzina A, Ponitka A (1997) Effect of genotype and media composition on embryoid induction and plant regeneration from anther culture in triticale. J Appl Genet 38:253-258

Sozinov A, Lukjankuk S, Ignatova S (1981) Anther cultivation and induction of haploid plants in Triticale. Z Pflanzenzücht $86: 272-285$

Stasolla C, Belmonte MF, Tahir M, Elhiti M, Khamiss K, Joosen R, Maliepaard C, Sharpe A, Gjetvaj B, Boutilier K (2008) Buthionine sulfoximine (BSO)-mediated improvement in cultured embryo quality in vitro entails changes in ascorbate metabolism, meristem development and embryo maturation. Planta 228:255-272. https ://doi.org/10.1007/s00425-008-0735-z

Sunderland N, Xu ZH (1982) Shed pollen culture in Hordeum vulgare. J Exp Bot 33(5):1086-1095. https://doi.org/10.1093/jxb/33.5.1086

Szarejko I (2003) Doubled haploid mutant production. In: Maluszynski M, Kasha KJ, Forster BP, Szarejko I (ed) Doubled haploid production in crop plants: a manual. Kluwer Academic Publisher, Dordrecht. pp 351-361. doi: 10.1007/978-94-017-1293-4.

Targońska M, Hromada-Judycka A, Bolibok-Brągoszewska H, Rakoczy-Trojanowska M (2013) The specificity and genetic background of the rye (Secale cereale L.) tissue culture response. Plant Cell Rep 32(1):1-9. https://doi.org/10.1007/s00299-012-1342-9

Tenhola-Roininen T (2009) Rye doubled haploids: production and use in mapping studies. In: Marjomäki V (ed) Jyväskylä studies in biological and environmental science. University of Jyväskylä, Jyväskylä, p 93

Tenhola-Roininen T, Tanhuanpää P, Immonen S (2005) The effect of cold and heat treatment on the anther culture responce of diverse rye genotypes. Euphytica 145:1-9. https://doi.org/10.1007/s1068 $1-005-8229-6$

Thomas E, Hoffmann F, Wenzel G (1975) Haploid plantlets from microspores of rye. Z Pflanzenzücht 75:106-113

Vernoux T, Wilson RC, Seeley KA, Reichheld JP, Muroy S, Brown S, Maughan SC, Cobbett CS, Van Montagu M, Inze D (2000) The ROOT MERISTEMLESS1/CADMIUM SENSITIVE2 gene defines a glutathione: dependent pathway involved in initiation and maintenance of cell division during postembryonic root development. Plant Cell 12:97-110. https://doi.org/10.1105/tpc.12.1.97

Wang XZ, Hu H (1984) The effect of potato II medium for triticale anther culture. Plant Sci Lett 36:237-239. https://doi. org/10.1016/0304-4211(84)90175-5

Wędzony M, Marcińska I, Ponitka A, Ślusarkiewicz-Jarzina A, Woźna J (1999) Genetic control of haploid embryo formation in triticale maize crosses. In: Wędzony M, Skrudlik G, ed, Wide crosses in cereals-problems and applications. Proceedings of the conference of COST action 824 'gametic embryogenesis', Kraków 18-20 February 1999, pp 40-42

Wenzel G, Thomas E (1974) Observations on the growth in culture of anthers of Secale cereale. Z Pflanzenzücht 72:89-94

Wenzel G, Hoffmann F, Thomas E (1976) Heterozygous microsporederived plants in rye. Theor Appl Genet 48:205-208. https://doi. org/10.1007/BF00527372

Wenzel G, Hoffmann E, Thomas E (1977) Increased induction and chromosome doubling of androgenetic haploid rye. Theor Appl Genet 51(2):81-86. https://doi.org/10.1007/BF00299481

Zaffagnini M, Bedhomme M, Lemaire SD, Trost P (2012a) a)The emerging roles of protein glutathionylation in chloroplasts. Plant Sci 185-186:86-96

Zaffagnini M, Bedhomme M, Marchand CH, Morisse S, Trost P, Lemaire SD (2012b) b) Redox regulation in photosynthetic organisms: focus on glutathionylation. Antioxid Redox Signal 16:567-586

Zechmann B (2014) Compartment-specific importance of glutathione during abiotic and biotic stress. Front Plant Sci 5:566. https://doi. org/10.3389/fpls.2014.00566

Zeng WY, Tang YQ, Gou M, Sun ZY, Xia ZY, Kida K (2017) Comparative transcriptomes reveal novel evolutionary strategies adopted by Saccharomyces cerevisiae with improved xylose utilization capability. Appl Microbiol Biotechnol 101(4):1753-1767. https ://doi.org/10.1007/s00253-016-8046-y

Zhuang JJ, Xu J (1983) Increasing differentiation frequencies in wheat pollen callus. In: Hu H, Vega MR (eds) Cell and tissue culture techniques for cereal crop improvement. Science Press, Beijing, p 431

Zimny J (1993) Somatic embryogenesis of rye (Secale cereale L.) in the in vitro culture. Institute of Plant Breeding and Acclimatization Publisher, Radzikow, pp 59-61

Żur I, Dubas E, Krzewska M, Sánchez-Díaz RA, Castillo AM, Vallés MP (2013) Changes in gene expression patterns associated with microspore embryogenesis in hexaploid triticale $(\times$ Triticosecale Wittm.). Plant Cell Tiss Org 116:261-267. https://doi. org/10.1007/s11240-013-0399-7

Żur I, Dubas E, Krzewska M, Janowiak F, Hura K, Pociecha E, Bączek-Kwinta R, Płażek A (2014) Antioxidant activity and ROS tolerance in triticale $(\times$ Triticosecale Wittm.) anthers affect the efficiency of microspore embryogenesis. Plant Cell Tiss Org 119:79-94. https://doi.org/10.1007/s11240-014-0515-3

Żur I, Dubas E, Krzewska M, Zieliński K, Fodor J, Janowiak F (2019) Glutathione provides antioxidative defence and promotes microspore derived embryo development in isolated microspore cultures of triticale ( $\times$ Triticosecale Wittm.). Plant Cell Rep 38:195-209. https://doi.org/10.1007/s00299-018-2362-x

Publisher's Note Springer Nature remains neutral with regard to jurisdictional claims in published maps and institutional affiliations. 